\title{
Usage of state-of-the-art Web technologies: moocher or maker of millions?
}

\author{
Celesti van der Westhuizen \\ JD Group \\ celesti@jdg.co.za
}

\section{Contents}

1. Introduction

2. Enterprise background

3. State-of-the-art technology

4. Return on investment

5. Training

6. JD Group case study - Gentia Web

7. User survey

8. Challenges envisaged

9. Lessons learned

10. Conclusion

11. References

\section{Introduction}

Many companies are beginning to recognise information as its most important asset to keep an eye on the business, keeping its core quality growth in check and working proactively to predict and avoid surfacing problems.

The proliferation of LANs and the Internet/intranet makes the delivery of business information a reality. These technologies bring an intuitive and meaningful interface to the office of many a manager, by which instantaneous and accurate decisions can be made.

Many companies have either embarked or are in the process of implementing data warehousing projects that undeniably are expensive. Without a maturing attitude to technology as an enabler and not an end in itself, technology is futile.

To ensure success, the following hurdles still need to be mounted:

- Focus on technology to meet business requirements

- The confused end-users need to be better educated. 


\section{Enterprise background}

The JD Group, mass consumer financier, is South Africa's leading furniture retailer operating through five chains that cover a spectrum of consumer needs. It is listed on the Johannesburg Stock Exchange in the Industrial sector's retail category.

The five chains are Bradlows, Giddy's, Joshua Doore, Price 'n Pride and Russells. While each chain has its own identity, merchandise range and marketing profile, they all concentrate on offering customers a wide range of quality furniture, appliances and home entertainment and consumer finance products supported by a high level of personal service.

JD Group serves the mass market through 671 stores in urban and rural areas across Southern Africa and through 12 stores in Poland, generating annual revenue in excess of R3.4 billion and an annual cash inflow of some R3.1 billion from trading activities.

\section{State-of-the-art technology}

Over a period of 12 years, the total expenditure in the JD Group was approximately R274 million, an estimate derived from the fact that $8 \%$ of the annual budget of the company is allocated to the maintenance and smooth operation of the IT Department.

The JD Group has the largest retail satellite network in the southern hemisphere and has one of the most extensive data warehouses in furniture retail. Visibility, a stock replenishment system, is also in use, as well as Transact, an automatic credit granting system. Transact takes away personal feelings and gives merit based on information according to preset scorecards. Within seconds a person's credit rating is verified at ITC and a valid credit rating is done within seconds. The focus however for this study will be on the satellite network, EDW, and most importantly Gentia.

\subsection{Satellite network}

In 1995 the V-sat satellite network was acquired from Telkom-Hughes Satellite systems. Seven hundred branches and warehouses in South Africa are using the satellite network extensively for data transfer only. It is an important infrastructure on which the intranet is operating. The best transfer rate for any transaction is $3 \frac{1}{2}$ seconds where $2 \frac{1}{2}$ seconds delay is for latency and a one second delay is for server response.

\subsection{Data warehouse (EDW/DSS)}

The first iteration of the enterprise data warehouse (EDW) was implemented with the primary focus on detailed sales analysis. The second iteration, focusing on customer information, lend an opportunity to analyse and evaluate our target market with astounding grace.

The total relational database size is 129 gigabytes of data. EDW is running on a quad processor server with 2 Gbyte of memory, 2 x disk arrays of 360 Gbytes of RAID Disk and a tape library. In the near future, an upgrade on the abovementioned hardware is planned. Product information is being updated on a daily basis, while client information is being updated once a month. All information is reconciled at month-end. The currency of the information in the EDW enables a drilldown to very specific client information, account information, what products they might have bought, etc. It also enables one to analyse trends of consumer behaviour, for example, the average age of people buying a specific product. 
To make this information accessible to top management, often queries must be executed by sorting and filtering through tables with over 100 million records. The average time for a big query calculating 32000 records takes four minutes to complete.

Together, V-sat and EDW play an important role in the information management and marketing departments in the Group. A major priority is to develop a component-based architecture that will enable the delivery of Web-based services to all facets of the Group. The EDW and V-sat architecture will form the basis of the new branch processing system and will allow inter alia for the extension and integration of the supply chain.

A major priority will remain to continually enhance the enterprise data warehousing information. Comprehensive customer and product information will provide valuable insight into more targeted offerings to the customer base.

\subsection{Gentia}

Gentia, a software package that uniquely combines work group, EIS, DSS and OLAP functionality, is used as decision support system throughout the company.

Gentia incorporates GentiaDB, a fully scaleable, robust multidimensional database server that allows a virtually unlimited amount of data to be stored and retrieved. Because of the advanced architecture that supports Gentia, any application can be operated in stand-alone mode, or distributed across multiple clients and servers with mixed operating systems and graphical interfaces.

Gentia uses agent technology to support the enterprise information systems developed for today's complex client/server environment. The agent technology is used to automate tasks, such as automating the loading of day-end, month-end and target data, transmitted by the satellite network.

The Internet, and the WWW in particular, is tailor made for Gentia. Web technologies are being exploited by the electronic exchange of information. Intranets are being implemented to gain that extra edge vital for outperforming the competition in the global market place.

All these technologies were developed and put in place with the enticement of quality profit growth at branch level and creating wealth in the company. But if the end-user, the key roleplayer in the creation of this wealth, perceives the Web technology as dominating, inaccurate and complicated to use, does it defeat the purpose of the expenditure of millions?

\section{Return on investment}

Speed, efficiency, productivity and quality of service: these are but a few of the expectations customers have of retailers such as the JD Group. The most appropriate person, who can directly endorse these expectations of the retail industry, is the branch manager and his team. The retail industry is motivated by its desire to please the market, and restricted by the need for low margins and cost restraints. Technology is not the solution, merely the enabler (Etzman 2001)

Investment in any technology is no different to any other capital investment - it must show a return (Leonard 2001). Any technology that is not producing results and contributing to the bottom line is a waste of money. 
Return on investment (ROI) is a measure of the monetary benefits obtained by an organisation over a specified time period in return for a given investment in a training programme (McGrath and Schneider 1997).

OR

Return on investment is the extent to which the benefits (outputs) of training exceed the costs (inputs) (McGrath and Schneider 1997).

\subsection{Four basic criteria for return on investment}

The four basic criteria for ROI are:

- Achieving business goals

- Minimizing risk

- Rate of return on investment required

- Acceptance within the organization (PeopleSoft 1997a).

\subsubsection{Different strokes for different folks (achieving business goals)}

Where you stand on ROI depends on where you sit. Different levels of management make different sorts of decisions, so it is appropriate that they use different measures of ROI.

Table 1 Different measures of ROI for different levels of anagement (Cross 2001)

\begin{tabular}{|c|c|c|c|}
\hline Function & Goal & Measurement & Scope \\
\hline Branch anager & Close skills gap & $\begin{array}{l}\text { Individual } \\
\text { performance }\end{array}$ & \multirow{2}{*}{$\begin{array}{l}\text { Business units, } \\
\text { specific training }\end{array}$} \\
\hline Business units CEO & $\begin{array}{l}\text { Achieve business } \\
\text { goals }\end{array}$ & $\begin{array}{l}\text { Project goals, } \\
\text { business metrics }\end{array}$ & \\
\hline Corporate staff & $\begin{array}{l}\text { Choose the best } \\
\text { alternative }\end{array}$ & $\begin{array}{l}\text { Financial metrics, } \\
\text { business case }\end{array}$ & \multirow{2}{*}{$\begin{array}{l}\text { Enterprise, e-learning } \\
\text { infrastructure }\end{array}$} \\
\hline $\begin{array}{l}\text { Executive } \\
\text { management }\end{array}$ & $\begin{array}{l}\text { Gain competitive } \\
\text { advantage, } \\
\text { transformation }\end{array}$ & $\begin{array}{l}\text { Business case, } \\
\text { shareholder value }\end{array}$ & \\
\hline
\end{tabular}

All these goals are valid, in fact, they complement one another.

The more the various managerial groups understand each other, the better the odds that they will make sound decisions.

- Short-term goals need to be sorted from the long-term ones

- Undertakings must align with strategic initiatives

- Communication of these goals and how they should be achieved should be made by the use of information technology. To achieve these business goals, risk should be minimized (Cross 2001)

\subsubsection{Minimizing of risk}


Risks must be weighed against rewards.

\subsubsection{Rate of ROI required}

Financial value (e.g. cost savings) is not always the best indicator of IT's worth to an organization. Alone, ROI does not provide important information that IT organizations and senior management should consider, for example, the business value of IT projects (Recourse Management Systems 2001)

\subsubsection{Acceptance within the organization}

Converting data into hard monetary values is essential to create acceptance within the organization. But how can intangible benefits, such as job satisfaction, be translated into rands?

Before training, ask employees to rate their job satisfaction on a five-point scale. When they've been using their newly-acquired skills for a while, ask them to do the rating again. Then, tie the increase in job satisfaction to a higher level of customer service. Better customer service means, in the end, increased revenue. An intangible benefit like job satisfaction has been directly tied to the bottom line (Webb 1999).

\section{Training}

Training is one of the many actions that an organization can take to improve its performance and profitability. There are many alternative approaches available to training to provide better value and increased benefits, for an organization e.g.

- Classroom training

- On-job training

- Self study

- On-line (Shepherd 1999).

\section{JD Group Case study - Gentia Web}

Over a period of 12 years computer technology has been used by the JD Group and, by the acquiring of the satellite network, it has become good at capturing and storing data in formats optimized for effective storage.

Although hardware can collect and store data, as in Gentia, it is the software interface which presents data in such a way that meaning can be derived. However, human capability is still required to process data for meaning.

The Gentia-software consists of an additional piece of software, which is the Web-based addition to the full-scale version, used by head office users.

The Gentia Web suite was initially acquired for an estimated R12 000 (for licences), and the application was developed with the functioning of financial services in mind. Currently, there are a number of applications available on Gentia Web, which enables the branch manager on the basic level of management to look at his branch information in the same 
dimensions as the MD of the company.

- Flash and key resource indicators (KRIs)

There are three applications containing basic financial information, widely used by all, a daily and monthly level.

- Communication status

There is a communication status indicator to display whether daily information was updated on the application

- Financial services

The financial service application is why Gentia Web was initially developed, and is currently under development due to an alliance with the Nedcor group for the enhancement of the financial services function.

- Team development ratings

This is a respected report used on a monthly scale to rate and weight the performance of branches as a team in their respective region and division. The executive chairman of JD Group, Mr David Sussman was the initiator of the report and states in the annual report for 2000: 'Developing our people at all levels is fundamental to introduce our new concept of "team based competency". The old maxim of "the chain being as strong as its weakest link" holds true for our business. Our managers are now rated by the strengths of their respective teams.' (JD Group Annual report 2000)

Thus the outcomes of this report are on the personal agenda of every manager in the company (Furphy 2001).

\section{User survey}

A certain number of branches were personally visited as a very small sample to represent each business unit in the company. It was disturbing to find that none of the branches in the sample were using the Gentia Web application. They were aware of the existence of the application, because the shortcut icon was already created on each branch manager's desktop, and they have heard about the team-based report in meetings, etc. They claim that they were not trained or made aware what the application was used for and what it could mean to them.

According to Andre (2001), users who should have access abdicate their responsibility when they do not have access. Even if they do have access to the information, they do not know how to apply that information to solve problems.

A short period of time (less than 10 minutes) was spent with each branch manager to explain and demonstrate the purpose of the application. Their first reaction was that it is redundant and another source of information overload (Figure 1). Since the first three applications are a duplication of their branch performance summary report - the most common source of financial information and branch performance - they immediately compared Gentia Web's figures with the figures on their branch reports that they have printed. As soon as they were satisfied that the information corresponded perfectly and correctly with their trusted information, they seemed to show a little more interest and were a bit amused, but still not convinced. However, as the author explained the significance and instantaneous availability of historic data and the various dimensions in which information can be viewed, all of them began to understand the opportunities available in the application for their branches. 
The team-based report was ultimately the seller of the application, when none of the other applications could capture the branch manager's attention. Whereas each branch manager could see proof of how his management skills were rated and weighted by top management, he appreciated the value of the application.

\subsection{The Gentia Web application}

Security features are built into the Gentia Web application to enable each branch manager to see only his branch's information, each regional manager to see only his own region and each divisional manager to see only his own division's figures (Figure 1).

Figure 1 Gentia Web login page or index page

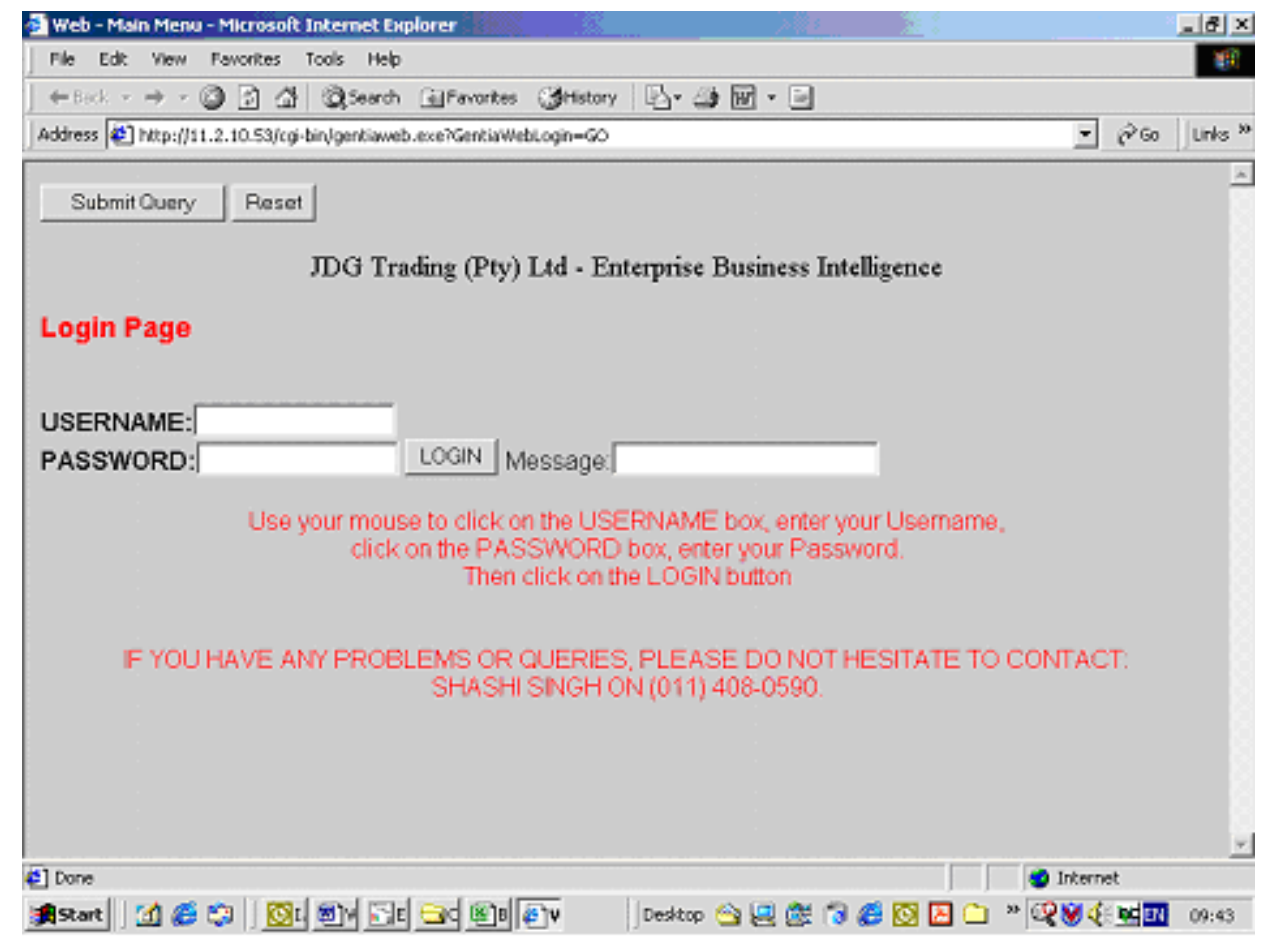

The menu in Figure 2 is enabled to show all the applications available in the head office application. Specific user permissions can be set that branch managers can only see those applications applicable to them.

Figure 2 Menu or site map of the Gentia Web application 


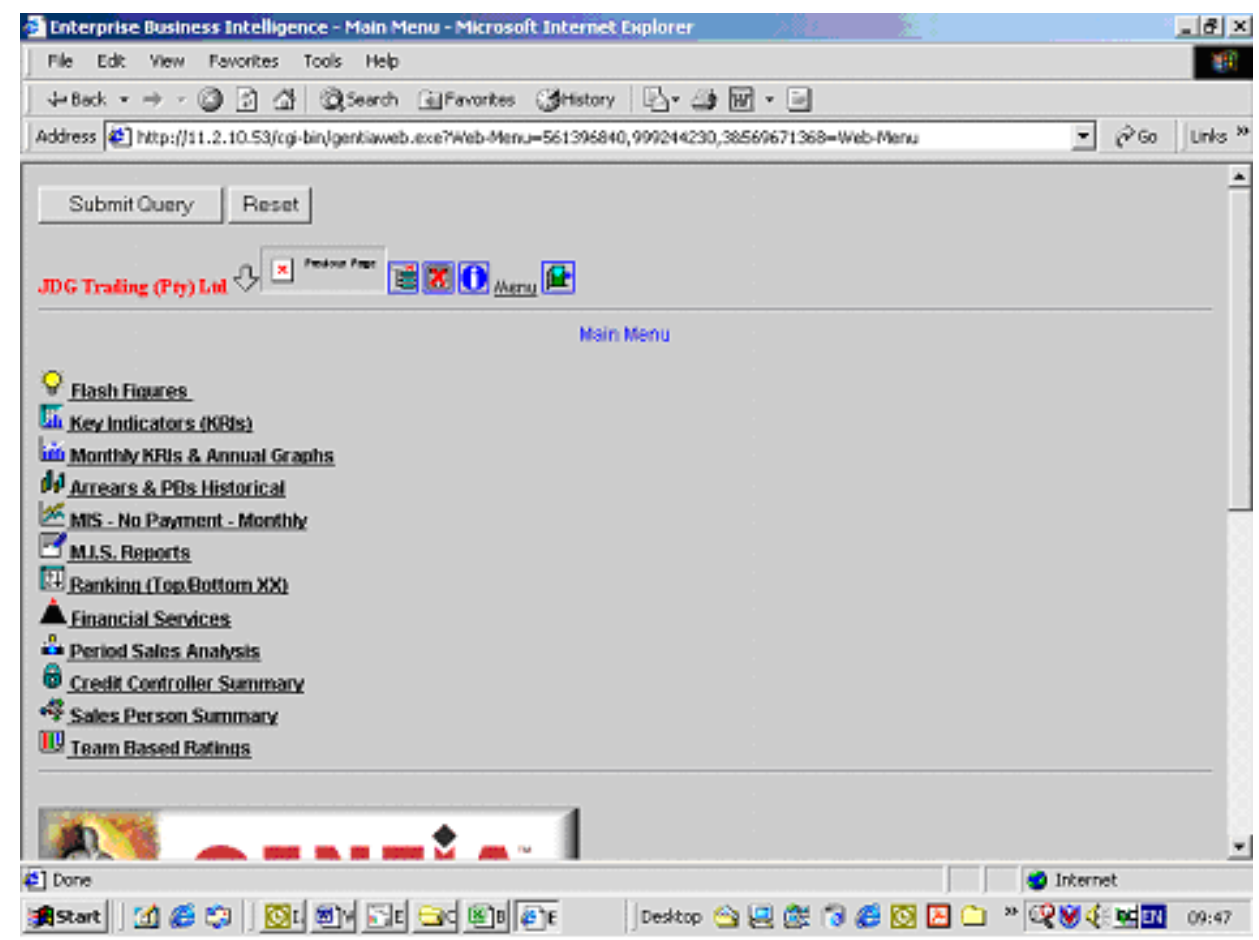

The intention of the application is to quickly establish day-to-day activity in the company. Flash figures are the most updated figures at the beginning of the day, and whenever there is a communication failure for some reason and the key resource indicators (KRIs) can not be updated, flash figures will almost always be available (Figures 3 and 4).

Figure 3 Flash figures

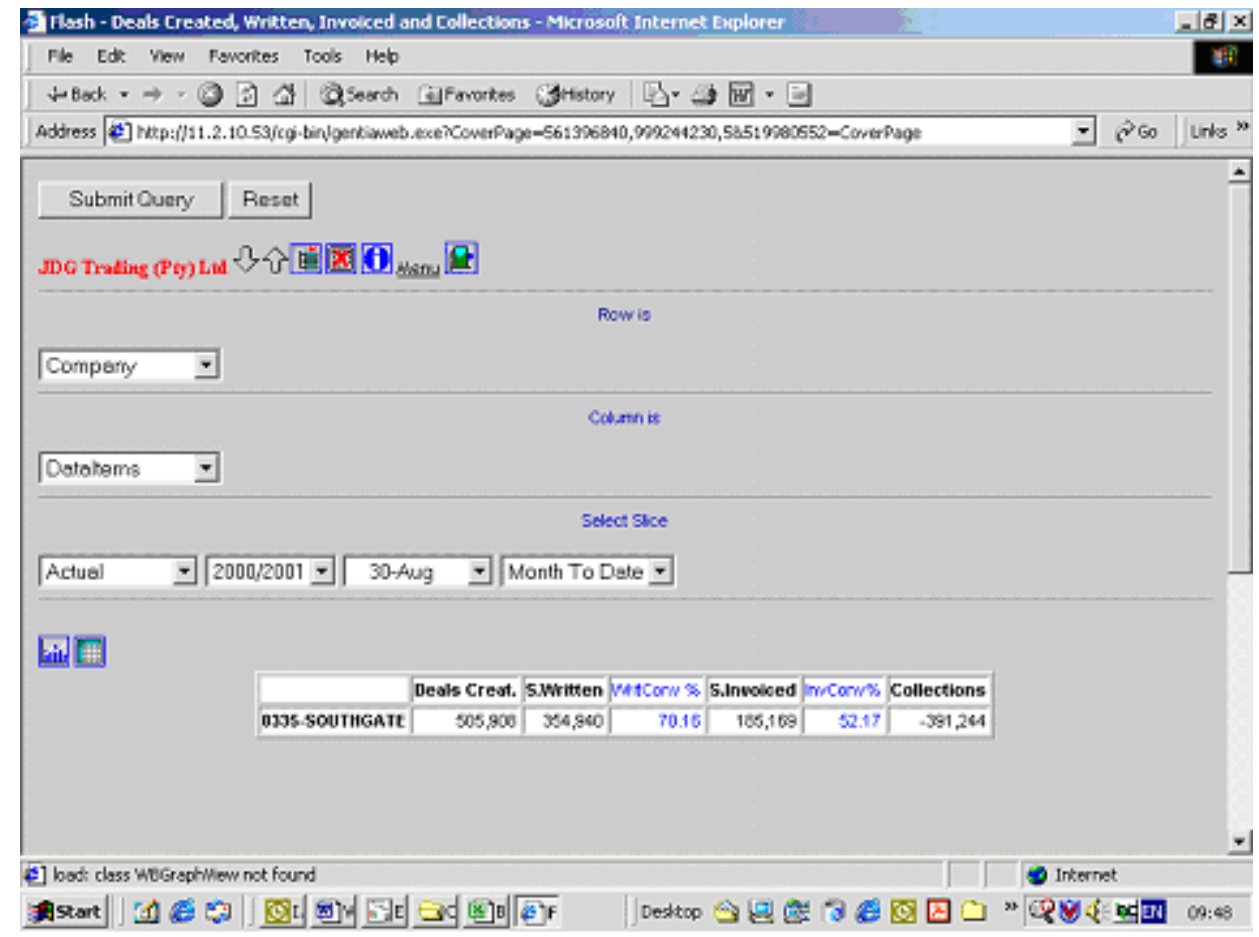

Figure 4 Key resource indicators (KRIs) 


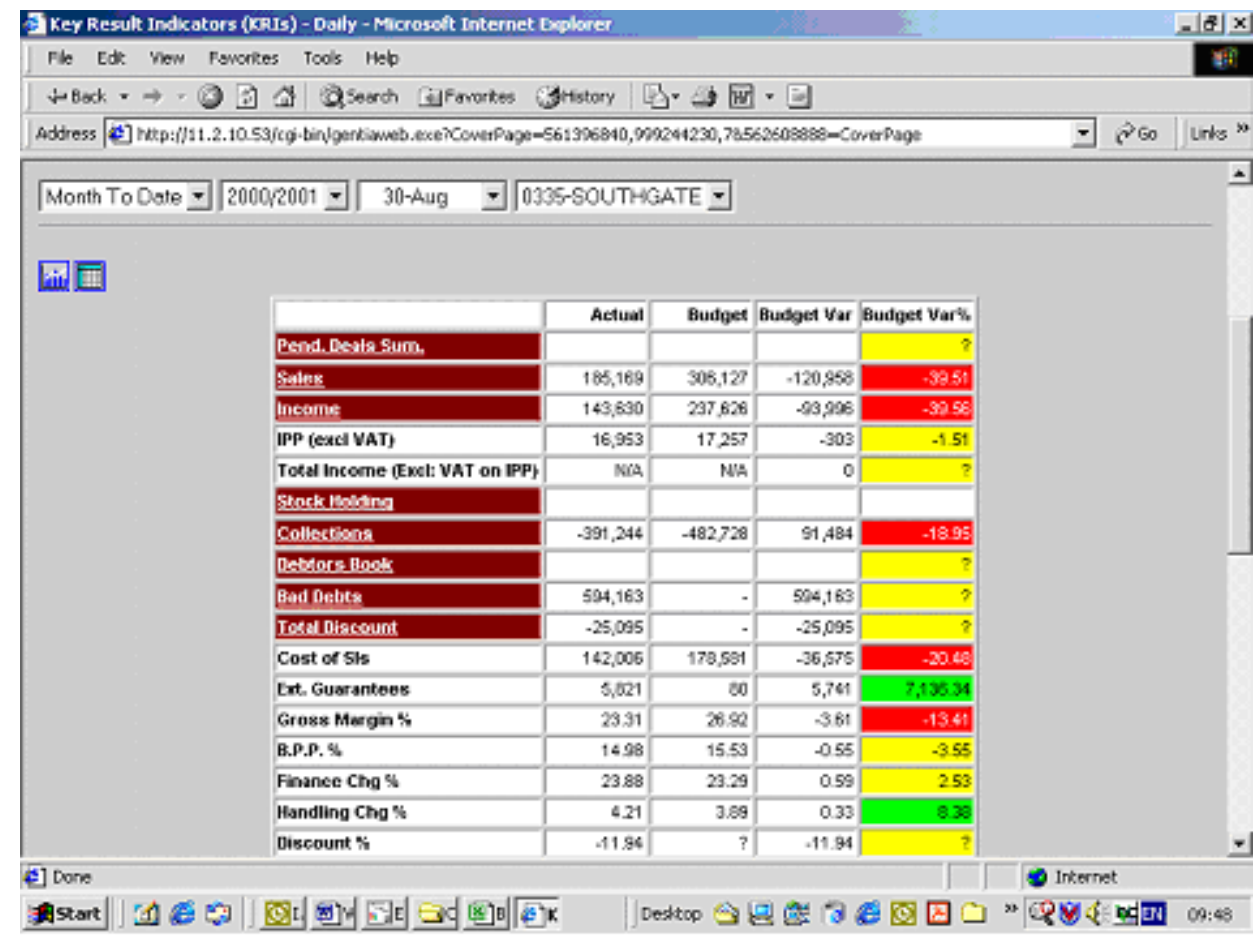

The KRIs are a complete transaction summary report. Wherever something is highlighted with a brown colour, the user could drill down to see a composition of the figures. Colour codes are also used to indicate where possible branch problems could lie.

If there could be co-operation between branch managers and people responsible for the total quality management (TQM) of the Gentia application, a very high standard of TQM for the application could be maintained.

Conventional bankers have been loathe to enter this market, providing JD Group with a tremendous advantage to capitalize on this opportunity. JD Group is poised to aggressively target this market and meet the real financial needs of the people in providing short, medium and long-term financial products (Figure 5). This application gives the branch manager insight on how they are performing (Figures 6a and 6b).

Figure 5 Financial services 


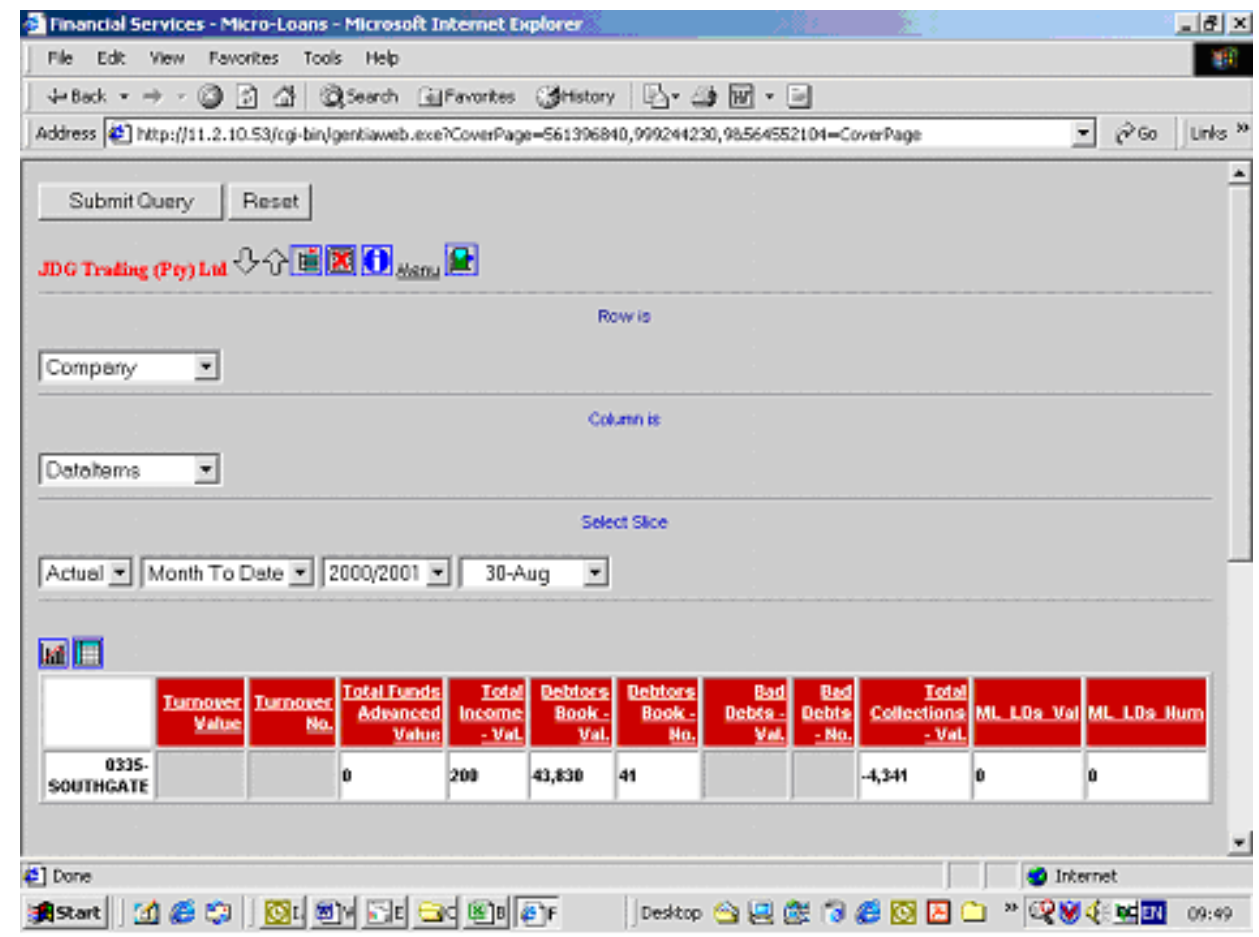

Figure 6a Team-based ratings

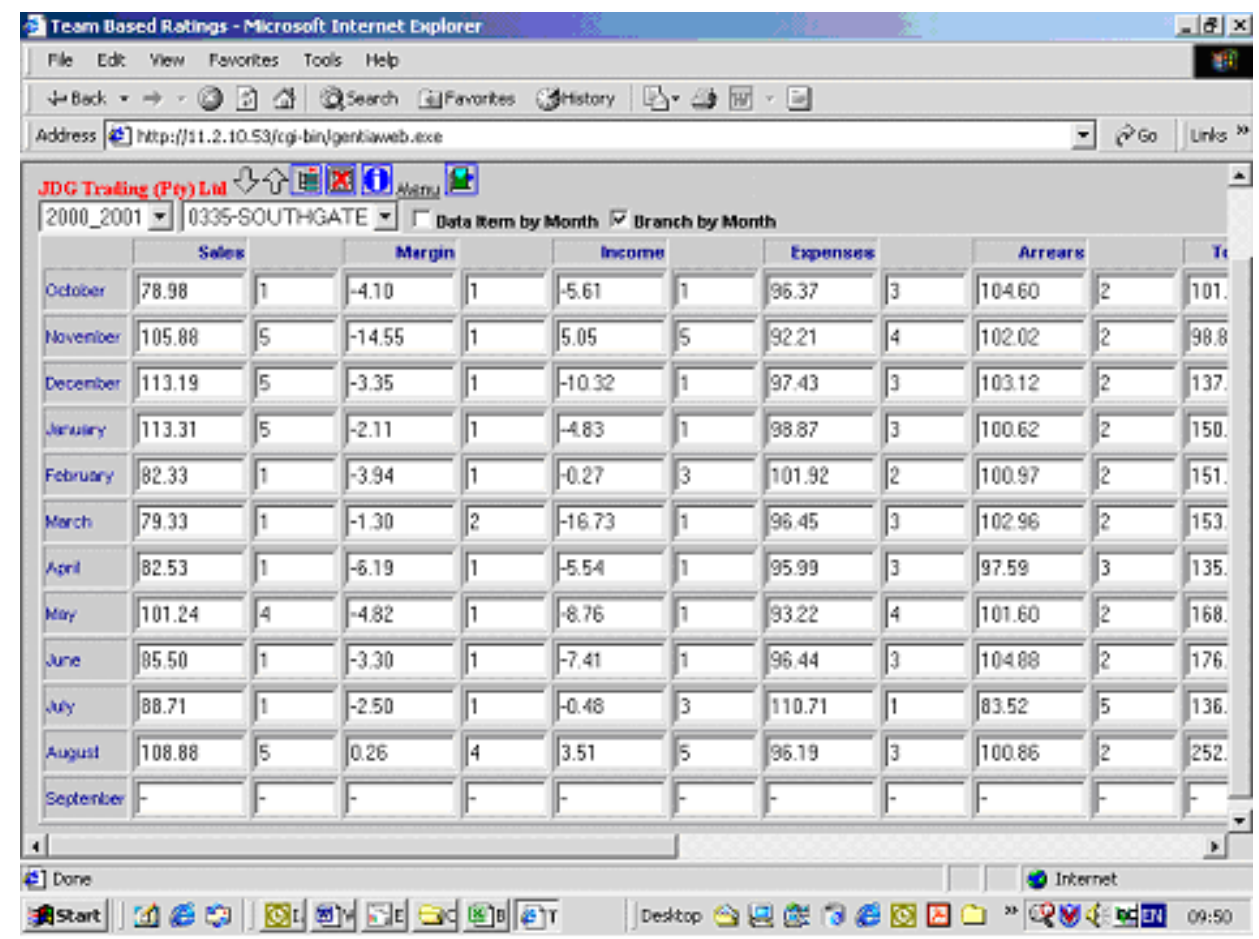

Figure 6b Team-based ratings 


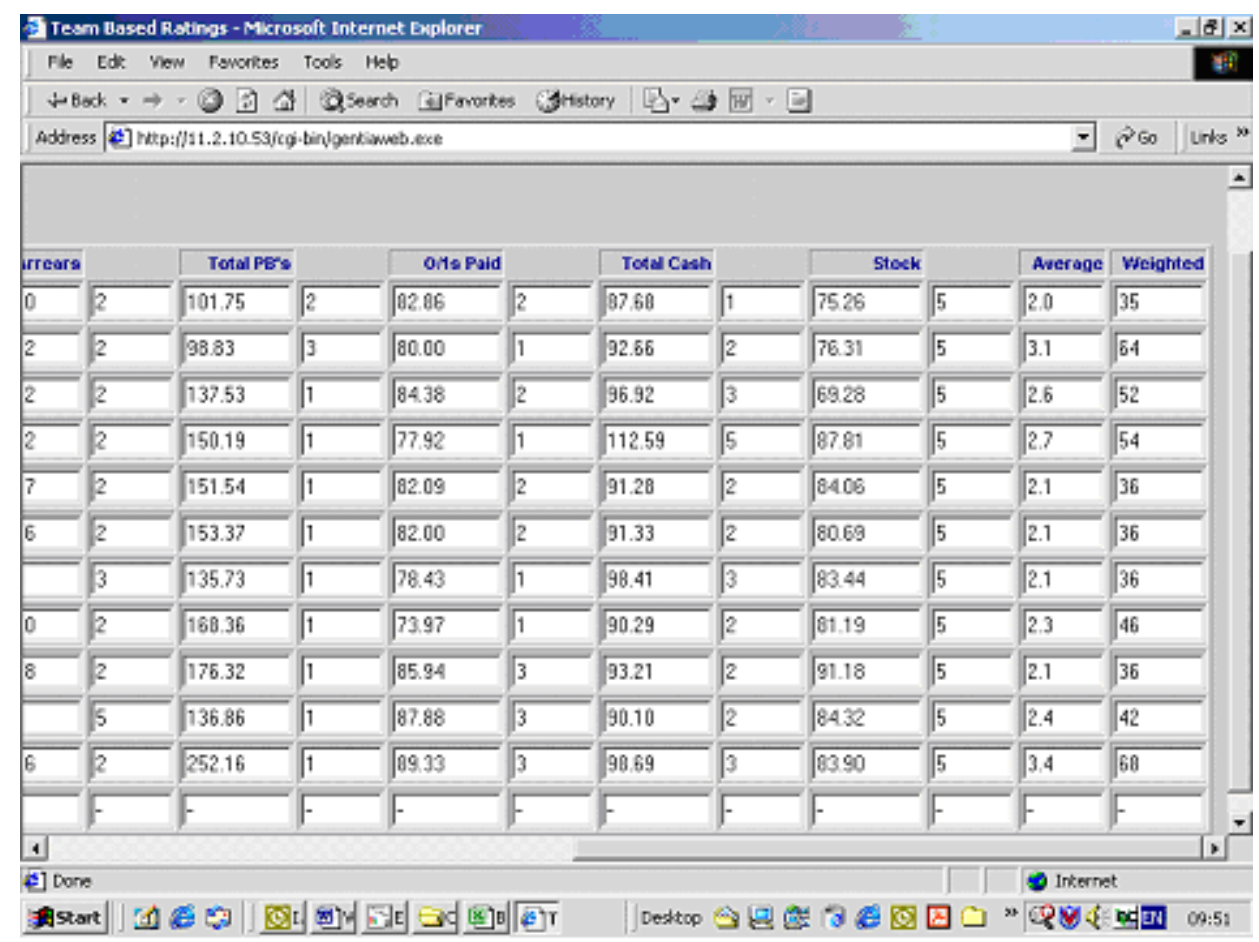

The team-based ratings rate the branch on nine criteria.

Each application has a choice of various dimensions, for example, look at the information with the row dimension as months and column dimension as company, or row as time span (difference between two financial years) and column as version (actual vs. budget), etc.

After the short demonstration, an end-user survey was completed by each of the branch managers. On face value, and in the relatively short period of time the branch managers had to evaluate the application, they rated it mostly as very good to excellent. They exclaimed that by using the application, they could be more aware of what was going on in the branch on a daily basis, and could work to achieve a more excellent rating percentage. Now they have a yardstick to which they could measure themselves.

'Small differences in compound interest lead to increasing, and finally staggering differences in capital accumulation' (Bugle 1999).

Organizations typically expect relevant members of staff to have a significant amount of knowledge as input to the process, but the people responsible do not necessarily have the know-how. Organizations should therefore ensure staff have the necessary technical skills to address problems and should train staff on how to turn data into meaningful information (Andre 2001).

By training these few branch managers, they have committed themselves to outperforming their previous achievements.

For instance, a certain branch that was visited had an average increase in weighting of 26\% on the team-based ratings between the financial months of July and August. As said by Zitzke (2001), 'Satisfied employees create satisfied customers'.

So, while branch managers work on individual performance as in Table 1, all the other levels of management will incrementally benefit and achieve excellence. 


\section{Challenges envisaged}

- 'The development and training of people is evolutionary and is a function that has no end. While it is important to recognize where we have been successful, it is equally important to accept that where there is human intervention there must always be room for improvement. Close scrutiny of the way we do things reveals great opportunity for improvement and unlocking value. Management's ongoing focus on development and succession remains a top priority'.

A big challenge will be to hold the executive chairman true to his promise, and explain the importance of training for return on investment on the application to management that is responsible for the application.

- The training should filtrate through the company hierarchy, from business unit CEO to branch level. Each manager should be held responsible to ensure thorough training.

- Another challenge is for the developers of these Web-based applications (Systems Department) to create designs that are more responsive to visitors' interests, thereby increasing customer loyalty (Andre 2001). Obviously there are certain restrictions that should be addressed in the design of the Gentia Web application.

\section{Lessons learned}

- Invest time in getting the criteria right

- Put consensus-building on center stage

- Link decision criteria to the passionate concerns of the decisionmakers

- Be creative in determining management concerns

- Continuously train people (PeopleSoft 1997b).

\section{Conclusion}

'Only if the technology improves the product or service to the customer, does he or she sense an improvement, which indicates that the technology improved the business process'. Return on investment is no myth; it is real and can contribute to the company's bottom line whenever adequate training is invested in the players that are held responsible for accumulation of wealth of the company. The best technology may be developed in a company and could lie there waiting for utilization, but human intervention is required to fulfil its full potential. No multimillion rand investment is ever enough to create wealth. All levels of management has to participate in the coaching and sharing of knowledge to build a stronger company.

\section{References}

Andre, S. 2001. Business Intelligence. IIQ, 1(2):57-58.

Bugle, J.C. 1999. Common sense on mutual funds. John Wiley \& Sons Inc.

Cross, J. 2001. A fresh look at ROI. [Online]. Available WWW: 
http://www.learningcircuits.org/2001/jan2001/cross.html 28/08/2000.

Etzman, L. 2001. POSitive thinking. Computer Week, 13/08/2001. [Online]. Available WWW: http://www.computerweek.co.za 28/08/2000.

Furphy, W. 2001. How to succeed in the new market. IIQ, 1(2): 44-45.

JD Group Annual Report, 2000. Re-inventing the market the JD Way.

Leonard, R. 2001. Technology and your future - a global perspective. IIQ, 1(2):68.

McGrath, G. and Schneider, A. 1997. Measuring intranet return on investment. [Online]. available WWW: http://www.intrack.com/intranet/ireturn.shtml 28/08/2000.

PeopleSoft, Inc. 1997a. PeopleSoft strategic investment model. [Online]. Available WWW: http://www.peoplesoft.com 28/08/2000.

PeopleSoft, Inc. 1997b. Is the strategic investment model really objective? [Online]. Available WWW: http://www.peoplesoft.com 28/08/2000.

Resource Management Systems Inc. 2001. Usage of ROI calculations in IT project decisions. [Online]. Available WWW: http://www.rms.net/lc_faq_other_roicalc.htm 28/08/2000.

Shepherd, C. 1999. Assessing the ROI of training. [Online]. Available WWW: http://www.fastrak-consulting.co.uk/tactix/features/tngroi.htm 28/08/2001.

Webb, W. 1999. Show me the return. Technology training. [Online]. Available WWW: http://www.trainingsupersite.com/ittrain/pastissues/november99/ nov99coverstory.htm

Zitzke, A. 2001. The Power to know. WebTelegraph. [Online]. Available WWW: http://www.webtelegraph.co.za 28/08/2000.

\section{Disclaimer}

Articles published in SAJIM are the opinions of the authors and do not necessarily reflect the opinion of the Editor, Board, Publisher, Webmaster or the Rand Afrikaans University. The user hereby waives any claim he/she/they may have or acquire against the publisher, its suppliers, licensees and sub licensees and indemnifies all said persons from any claims, lawsuits, proceedings, costs, special, incidental, consequential or indirect damages, including damages for loss of profits, loss of business or downtime arising out of or relating to the user's use of the Website.

Published by InterWord Communications for the Centre for Research in Web-based Applications, 
Rand Afrikaans University 